\title{
Solid-Liquid Interfacial Free Energy of Water: A Molecular Dynamics Simulation Study
}

\author{
Jun Wang, Yuk Wai Tang, and X.C. Zeng ${ }^{1}$ \\ Department of Chemistry, University of Nebraska-Lincoln, Lincoln, Nebraska 68588
}

1 *Electronic Mail: xczeng@phase2.unl.edu 


\section{Supporting Information}

1. Constant stress and temperature (NST) simulation using Berendsen barostat.

In this simulation we used the same parameters as used in the NPT simulation presented in the manuscript, except that we used the Berendsen barostat to allow the change of both size and shape of the box.
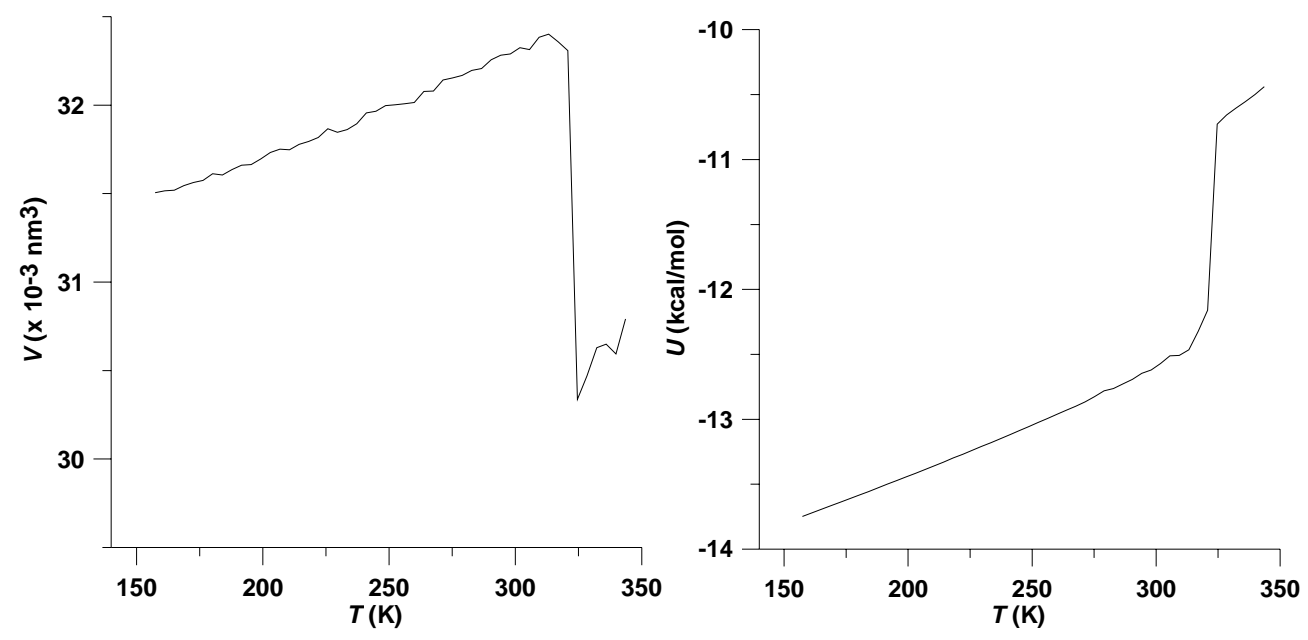

Fig. S1 (a) Volume vs. temperature (TIP4P-Ew)

(b) Potential energy vs. temperature (TIP4P-Ew)

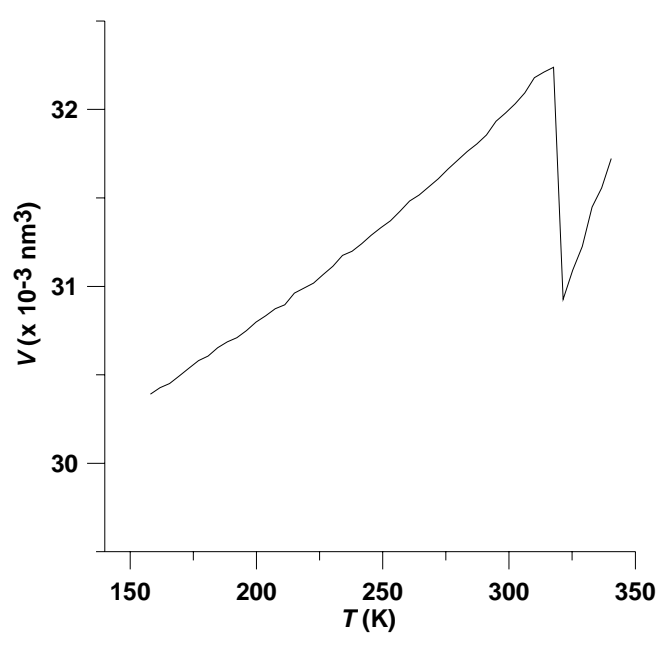

(c) Volume vs. temperature (TIP5P-Ew)

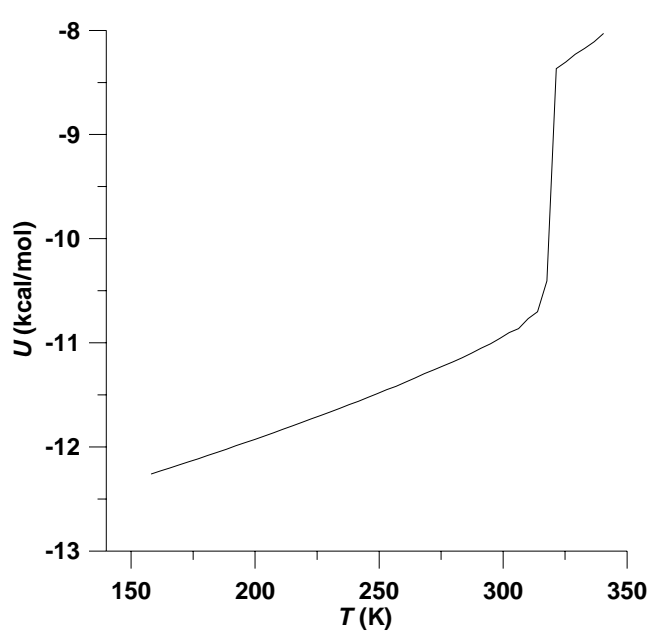

(d) Potential energy vs. temperature(TIP5P-Ew)

These figures show that changing box shape does not alter the superheating limit for TIP4P-Ew (321 K), but slightly increases the maximum superheating for TIP5P-Ew from 314 $\mathrm{K}$ to $317 \mathrm{~K}$. 
2. The effect of system size was tested by using a larger system including 2592 molecules. The initial size of the box also increased from $2.685 \mathrm{~nm} \times 3.100 \mathrm{~nm} \times 2.923 \mathrm{~nm}$ to 4.027 $\mathrm{nm} \times 4.650 \mathrm{~nm} \times 4.384 \mathrm{~nm}$.

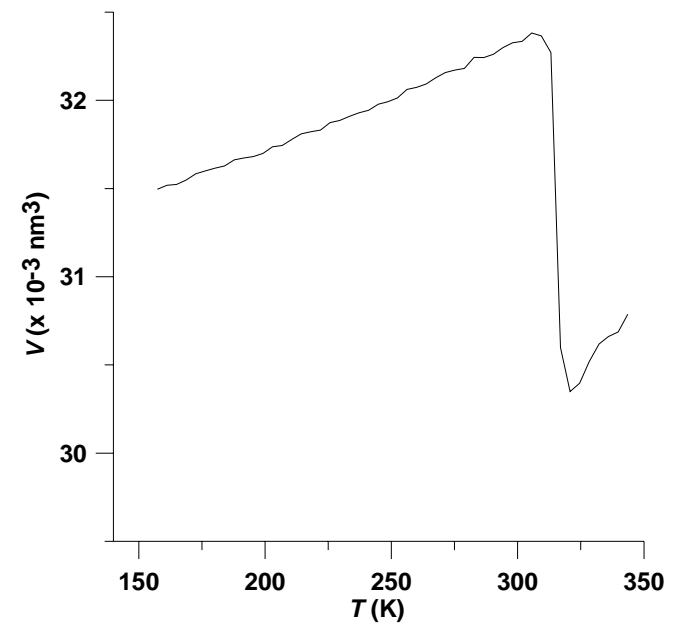

Fig. S2 (a) Volume vs. temperature (TIP4P-Ew)

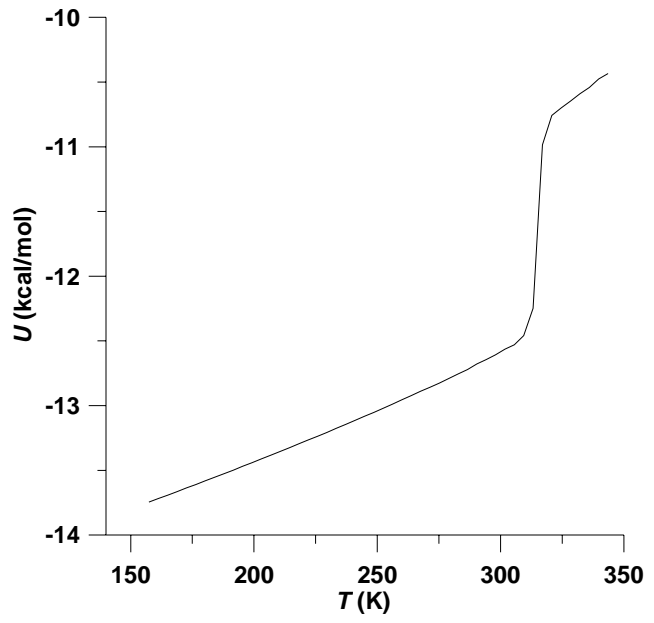

(b) Potential energy vs. temperature(TIP4P-Ew)

The results show that the superheating limit for TIP4P-Ew decreases slightly from 321K to 313K, but the difference is still within the error bar.

3. A snapshot after $1 \mathrm{~ns}$ two-phase (liquid water/ice) coexistence simulation with a large system size (initially 6144 ice and 6144 liquid water molecules) for the TIP5P-Ew model. The temperature was controlled at $254 \mathrm{~K}$ (NPT ensemble).

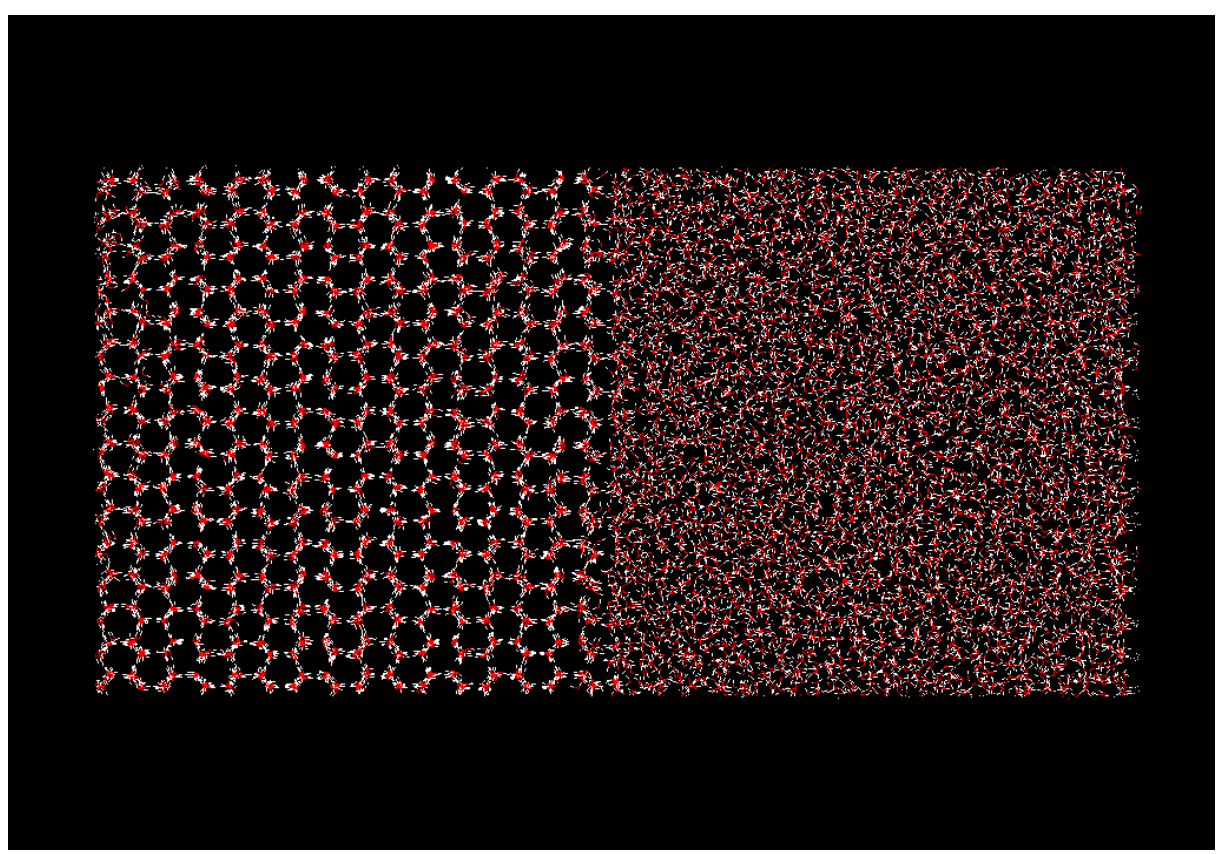

Fig. S3 Snapshot at the end of $1 \mathrm{~ns}$ simulation 
4. Calculated the interfacial free energy, assuming $270 \mathrm{~K}$ as the correct melting temperature for TIP5P-Ew.

Table S1 Comparison of the interfacial free energy based on $254 \mathrm{~K}$ or $270 \mathrm{~K}$ melting temperature.

\begin{tabular}{|c|c|c|c|c|c|c|c|c|c|}
\hline & $\begin{array}{l}T_{+} \\
(\mathrm{K}) \\
\end{array}$ & $\begin{array}{l}T_{m} \\
(\mathrm{~K}) \\
\end{array}$ & $\theta_{c}^{+}$ & $\beta$ & $\begin{array}{l}V_{s} \\
\left(\AA^{3}\right)\end{array}$ & $\begin{array}{l}V_{l} \\
\left(\AA^{3}\right)\end{array}$ & $\begin{array}{c}\Delta H_{m, v} \\
\left(\times 10^{8} \mathrm{~J} / \mathrm{m}^{3}\right)\end{array}$ & $\begin{array}{c}\gamma_{s l} \\
\left(\mathrm{~mJ} / \mathrm{m}^{2}\right)\end{array}$ & $\begin{array}{c}Q \\
(\mathrm{~K} / \mathrm{ps}) \\
\end{array}$ \\
\hline This work & $314(6)$ & $254(1)$ & $1.24(3)$ & $2.4(7)$ & $31.4(1)$ & 29.9(3) & $3.90(7)$ & $42(4)$ & 0.07618 \\
\hline $\begin{array}{c}\text { Fernandez } \\
\text { et al. }{ }^{24}\end{array}$ & $314(6)$ & $270(2)$ & $1.16(4)$ & $1.0(6)$ & $31.6(1)$ & $29.7(2)$ & $4.39(7)$ & $36(4)$ & 0.07618 \\
\hline
\end{tabular}

Extensive quantities are presented per molecule. Numbers in parentheses indicate the estimated error for the last digit(s) shown. 